\title{
Secret Chambers: The Insider Story of Cells and Complex Life
}

\author{
Martin Brasier. 2012. Oxford University Press, UK. Pp. 320 with 15 black and white illustrations and 8 pages of \\ color plates. $£ 16.99$ (hardcover). ISBN 9780199644001.
}

Reviewed by Farid Pazhoohi

Reviewer address: Department of Animal Science, College of Agriculture, Shiraz University, Shiraz, Iran pazhoohi@gmail.com

Received: December 8, 2013

Volume 5:91-93

Published: August 2, 2014

(C) 2014 Society of Ethnobiology

If Martin Brasier didn't want to pick science as his occupation, certainly he should have chosen to be a novelist, instead! Professor Martin Brasier who is a palaeobiologist at the Department of Earth Sciences, University of Oxford, in his book Secret Chambers: The Inside Story of Cells and Complex Life, takes us on a journey "to understand the complexity of the complex modern cell, and of the quest to rescue its hidden history from deep within the fossil record" (p. VI). Overall, in this book we learn about the formation and evolution of symbiosis between cells and the importance of symbiosis over the course of evolutionary history.

Brasier's explanations are bottom-up: he uses metaphor, analogy, and storytelling to explain scientific notions and concepts. In the first chapter, we learn about Robert Hooke's invention of the microscope and the historical situation which is that London was haunted by the plague. Hooke is the first person who reports the existence of fossils and many things that humans never imagined to exist before that time and also is the first one who conducted experiments on fossilization. With the story of the invention of the microscope, the book's journey begins.

We learn that due to this invention, Hooke is the person who coined some terms that we use in biology today, including cell and cell wall. Also here we learn that cells are Brasier's "secret chambers." "Each and every cell is like a secret chamber because it is surrounded by a protective wall made of fatty phospholipids. But it is also a secret chamber in another sense too, because its existence was entirely unknown until the invention of the microscope" ( $p$. 8).

The second chapter tells us about Charles Lyell,
Robert Brown, and Charles Darwin and the ideas that they were engaged with from a perspective that might be new to many professionals in the field. Here we learn about these scientists' observations and hypotheses leading to the discovery of cytoplasm, the nucleus, and the origin of the idea of the cell itself. We learn about Charles Lyell's grand idea and revolutionary explanation of gradual geological changes and his famous principle of uniformity, as well as Robert Brown's discovery of the cell nucleus. One geological theory turns into another which finally paves Darwin's road to his theory of the origin of species by means of natural selection.

In the third chapter, Brasier, a master storyteller with plenty of first person accounts, tells us stories about his work as the Ship's Scientist aboard the HMS Fawn. We learn about his on-board explorations of Caribbean marine ecosystems after his graduation in 1970. On Sargasso Sea, he and his colleagues haul algae from the sea to investigate under the microscope. He describes different algae species that he has encountered during his voyage and their traits such as their reproductive rate, ecology, and structure. Using metaphors, analogies, and through interesting explanations, Brasier compares the cell and its organelles with different parts of a ship and its belongings, and he signifies the function and importance of cellular membrane and wall. He asks, for example, how the chartroom is equal to the cell nucleus and how the passageways and the engine room resemble endoplasmic reticulum and mitochondrion, respectively.

In the fourth chapter, Brasier tells the story of his amazing and adventurous expedition encountering Pedro Bank, an offshore island to the southwest of Jamaica, and mapping out its reefs and shorelines 
beneath the sea water. We learn about symbiosis, "the living together of differently named organisms" ( $p$. 84), between protozoans and other organisms like algae. Brazier describes corals' symbiosis with phytoplanktons, which consequently makes them able to build the colorful coral reefs. Next, Brasier recounts his visit to South Cay Island and describes the structure of foraminifera which have algae as the endosymbionts, or organisms that live within other organisms. "Corals do it, sponges do it, even articulated clams do it. Sometimes it seems as though all the algae in seawater have been sucked inside animal tissues or inside the cells of giant protozoans leaving the seas themselves remarkably clear and blue" (p. 85).

In the fifth chapter, Brasier takes us to Trinidad Island, which lacks corals and symbionts. To provide an explanation for why, he explains how an ecosystem works and which factors contribute to maintenance of such ecosystems. He explains how vulnerable a marine ecosystem is, with its corals and their symbionts, to tiny changes in temperature and nutritional levels. Hence, Brasier clarifies the importance of stabilizing ecosystems and signifies the recent global temperature rise that has been causing the corals, protozoans, sponges, and other organisms to begin vanishing. Brasier tells us how these tiny organisms can affect the lives of other organisms on the planet, including our own. Brasier describes how energy flows within both living and extinct cells matter for ecosystems.

The next station in Brasier's journey is Barbuda Island. Brasier and his colleagues have interesting adventures while sampling and studying living reefs and algal mats. They find remains of extinct foraminifera that reveal the geological, climatological, and ecological changes of a billion years ago around the Caribbean. Brasier here again warns us about the negative consequences of human intervention in ecosystems.

In the seventh chapter, Brasier uses analogies and examples to explain the notion of the 'tree of life'. Interestingly, we learn that eukaryote lineage is mixed up: a kind of symbiont made up from different kinds of prokaryotes. We learn about the evolution and emergence of eukaryote cells from the symbiosis of chloroplasts and mitochondria with the prokaryote cells.

In the eight chapter, Brasier investigates the Sphinx and the great pyramids in Egypt, and shows that these ancient structures are made of nummulites, a kind of foraminifera-algal symbiosis. These nummulite fossils, that span from the Atlantic Coast in Europe toward the Persian Gulf and from the Himalayas to the Pacific Ocean near Thailand, are evidence that these regions have been once oceans. Exploring the mass extinction of organisms in the fossil records, we come to understand that the foraminifera-algal symbiosis has happened many times since 400 million years ago, and has faced extinction each time. Brasier reviews the repeated emergence and collapse of symbiosis across millions of years.

In the ninth chapter, we learn about the amazing story of the discovery of ancient (nearly 2000 million years old) bacteria in the fossils.

In the tenth chapter, Brasier explores Australia in general and the Lawn Hill crater specifically in search of their fossil records. He finds the earliest forms of modern cells in these fossil records and describes the mass extinction of symbiosis near the end of the early Cambrian. During his adventures in Australia, he collects bacterial fossil specimens and takes them to Oxford University for chemical analysis, finding no carbon isotope anomaly from two billion to one billion years ago. Brasier, who has coined this interval the Boring Billion, concludes that during that era there had been a blue water ecosystem.

Throughout all of his chapters until the last (eleventh) one, the author does not give us any hint where he wants to take us and one might wonder why the reader should read accounts on the author's journeys. One might even contemplate the aim of the book itself! From one point of view, this seeming lack of direction might be considered as the shortcoming of the book as the author does not make clear what point the book is going to make eventually. From the other point of view, this voyage into the unknown could be very joyful and mysterious-a Secret itself! Here he uses all the knowledge he has taught the reader over the first ten chapters to draw his conclusion in this final chapter. In this final chapter, Brasier explains the main point of the book. To grasp it, one must be patient and read on to the end: mass extinctions and the complexity of organisms are positively correlated!

Fossil species and their ecosystems have not changed much during a long period of geological time as "mass extinctions are-in geological terms-a relatively recent phenomenon. They have been lacking from much of the early history of life" (p. 212). The 
"early history" was during this Boring Billion when the stable environment provided for the permanent symbiosis between cell and its organelles leading to the emergence of symbionts (e.g., chloroplasts and mitochondria) inside the cell, which eventually formed eukaryotes. The speed of emergence and extinction of species has increased after 600 million years ago. Since 30 million years ago, emergence of symbiosis and their extinction have undergone huge bust-ups, leaving no time for any other organelle symbiosis to be permanent within the cells. In the rest of the eleventh chapter, using simple words, Brasier explains why this symbiosis has happened and why we humans as complex organisms and our ecosystems are predisposed more than ever to mass extinction.
The book's language is in simple form and is an easy read. Brasier's storytelling makes the book readable for laymen and graduate students. Even interested high school students can also understand and enjoy the reading. In addition, it is a very good book for helping general readers understand evolutionary processes and biological concepts, such as communication and energy flow. Interestingly, the author connects chapters and contents of the book masterfully and describes the stories of inventions and discoveries in detail, and the book gets more interesting the further we read. I highly recommended Secret Chambers for students of geology, paleobiology, and biology. Finally, I think Brasier has achieved his goal: "My hope is that the book will reveal just how rich and diverse have been our ways of thinking about the earliest life forms, written in words that can hopefully be read with ease and enjoyment" (p. VII). 